\title{
The Relapsing Polychondritis Damage Index (RPDAM): development of a disease- specific damage score for relapsing polychondritis
}

Philippe Mertz ${ }^{(1,2)}$, Alexandre Belot ${ }^{(3)}$, Ricard Cervera ${ }^{(4)}$, Tyng Yu Chuah ${ }^{(5)}$, Lorenzo Dagna ${ }^{(6)}$, Laura Damian ${ }^{(7)}$, Debashish Danda ${ }^{(8)}$, David D'cruz ${ }^{(9)}$, Gerard Espinosa ${ }^{(4)}$, Camille Frances ${ }^{(10)}$, David Jayne ${ }^{(11)}$, Kong Kok Ooi ${ }^{(12,13)}$, Eugene J. Kucharz ${ }^{(14)}$, Robert Lebovics ${ }^{(15)}$, Isabelle Marie ${ }^{(16)}$, Guillaume Moulis ${ }^{(17,18)}$, Stanford Peng ${ }^{(19)}$, Aman Sharma ${ }^{(20)}$, Noboru Suzuki ${ }^{(21)}$, Toshio Tanaka ${ }^{(22)}$, Ronald Van Vollenhoven ${ }^{(23)}$, Jean Sibilia ${ }^{(1,2)}$, Jacques Eric Gottenberg ${ }^{(1,2)}$, François Chasset ${ }^{(10)}$, Laurent Arnaud ${ }^{(1,2)^{*}}$

(1) Service de rhumatologie, Centre de Référence des Maladies Autoimmunes Systémiques Rares Est Sud-Ouest (RESO), Hôpital de Hautepierre, 1 Avenue Molière BP 83049, 67098 Strasbourg Cedex, France

(2) INSERM UMR-S1109, 67098 Strasbourg Cedex, France

(3) Department of Paediatric Nephrology, Rheumatology, Dermatology, Hôpital FemmeMère Enfant, Bron.

(4) Department of Autoimmune Diseases, Institut Clinic de Medicina i Dermatología, Hospital Clínic, Barcelona, Spain

(5) Department of Rheumatology and Immunology, Singapore General Hospital, Singapore.

(6) Unit of Immunology, Rheumatology, Allergy and Rare Diseases (UnIRAR), IRCCS San Raffaele Scientific Institute, Vita-Salute San Raffaele University, 20132 Milan, Italy 
(7) Rheumatology Department, Spitalul clunic Judetean de Urgenta Cluj. Cluj-Napoca, Romania.

(8) Department of Clinical Immunology and Rheumatology, Christian Medical College, Vellore, India

(9) Louise Coote Lupus Unit, Guy's Hospital, London, UK.

(10) Dermatology Department, Hôpital Tenon - Paris, France

(11) Department of Medicine, University of Cambridge, Cambridge, UK.

(12) Division of Rheumatology, National University Hospital, Singapore City, Singapore;

Yong Loo Lin School of Medicine, National University, Singapore City, Singapore.

Department of Internal Medicine and Rheumatology, Medical University of Silesia, Katowice, Poland. Department of Otolaryngology, From Mount Sinai St. Luke's and Mount Sinai Roosevelt affiliated with the Icahn School of Medicine at Mount Sinai, New York, NY, United States.

(16) Department of Internal Medicine, CHU Rouen-Bois Guillaume, Rouen cedex, France.

(17) Department of Internal Medicine, CHU de Toulouse, Toulouse, France; UMR 1027 Inserm-University of Toulouse, Toulouse, France; CIC 1436, CHU de Toulouse, Toulouse, France.

(19) Swedish Medical Center, Seattle, Washington, USA. 
Medicine, Postgraduate Institute of Medical Education and Research (PGIMER), Chandigarh, 160012, India.

(21) Institute of Medical Science and Department of Immunology and Medicine, St. Marianna University School of Medicine, Kawasaki, 216-8511, Japan.

(22) Department of Clinical Application of Biologics, Osaka University Graduate School of Medicine, Osaka University, Osaka 565-0871, Japan. Department of Clinical Immunology and Rheumatology, Academic Medical Center, Amsterdam, The Netherlands.

\section{*Corresponding author:}

Pr. Laurent Arnaud, Service de rhumatologie, Centre National de Référence des Maladies Autoimmunes et Systémiques Rares, Hôpital de Hautepierre, 1 Avenue Molière BP 83049, 67098 Strasbourg Cedex, France.

Phone: 0388128474 | Fax: 0388128290 | email: Laurent.arnaud@chru-strasbourg.fr 


\section{ABSTRACT}

Objectives: Relapsing polychondritis is a rare, multi-systemic and inflammatory condition of unknown origin. We currently lack a core set of measures to assess and follow damage in patients suffering from this condition. Our primary aim was to derive a disease-specific damage measuring tool for relapsing polychondritis, the Relapsing Polychondritis Damage Index (RPDAM).

Methods: We performed an international 4-round multicenter Delphi study during which experts were asked to rate the relevance of potential damage items for relapsing polychondritis (141 items were obtained from a literature review and 12 from expert suggestion), using a Likert scale. The selection of items for each subsequent round was based on the median rating of each item.

Results: Twenty-four experts from 11 nationalities participated in round 1 and 22 in rounds 2 , 3 and 4. From the initial 153 potential damage items, 44 items were selected during round 1, 30 items during round 2 and 16 during round 3. During round 4, we refined the index to a total of 17 items referring to ear nose and throat, eye, respiratory, cardiovascular and hematological systems as well as to treatment-related specific damage items.

Conclusion: We have developed by international consensus a scoring system to assess damage in patients with relapsing polychondritis. Following its validation, the RPDAM may contribute to improve the care of patients suffering from this rare condition as well as to standardize data collection for future clinical trials.

\section{KEYWORDS: Autoinflammatory diseases, Damage Index, Relapsing polychondritis}




\section{Introduction}

Relapsing polychondritis (RP) is a rare, severe, multi-systemic and progressive inflammatory condition involving cartilaginous structures (1), such as those of the ears, nose and of the laryngo-tracheo-bronchial tree (2). Additional clinical features include inflammation of the eyes, cardiovascular system (3), peripheral joints, inner ear, skin (4) and central nervous system (5-7). The rarity of RP makes it difficult to obtain detailed epidemiological data, but the prevalence of the disease has recently been estimated to be of $\approx 4.5$ per million $(8,9)$.

Currently, one of the difficulties in the assessment of RP is the lack of a standardized core set of measures. This leads to a non-standardized management of the disease and further limits the development of clinical trials. Importantly, the clinical spectrum of RP comprises very unique manifestations such as chondritides and deformities that are not fully captured by existing tools for other diseases. Also, the development of such tools would be a prerequisite to implement a treat-to-target approach in this disease.

Notably, distinguishing between disease activity and damage is a crucial challenge in daily clinical practice for accurate disease management; disease activity generally refers to reversible manifestations, while damage refers to irreversible manifestations that are unlikely to benefit from treatment escalation. In 2012, our group has derived a disease-specific activity score for RP by expert consensus (the Relapsing Polychondritis Disease Activity Index, RPDAI) (10) but we currently lack a disease-specific damage index. Building such a tool would help improving the care of RP patients, and would allow for clinical trials to rely on standardized assessment tools.

In this study, our primary aim was to derive a disease-specific damage index for RP, the Relapsing Polychondritis Damage Index (RPDAM), based on an international expert consensus using the Delphi method. 


\section{Methods}

\subsection{Definitions}

The steering committee defined "Damage" as irreversible manifestations of the disease that are unlikely to benefit from treatment escalation, ascertained by clinical assessment and present for at least 3 months. All damage manifestations reported had to occur after diagnosis of relapsing polychondritis.

\subsection{Study design}

The RPDAM study is an international multicenter study based on a 4-round Delphi method. A Delphi survey is a systematic process involving a series of rounds of data collection and analysis to derive expert consensus on a topic. This interactive process involves a panel of experts who are asked to rate a list of items during consecutive rounds while being provided with the aggregated responses of prior rounds. The study was headed by a steering committee composed of a rheumatologist specialized in the care of RP patients (L.A.), a dermatologist with a special interest in autoimmune diseases (F.C.) and a rheumatology resident (P.M.).

\subsection{Expert panel}

The expert panel was formed by contacting the main authors of all publications at least one series of $\geq 5$ RP patients between 2006 and 2016 in Pubmed and Embase. These experts where contacted individually by email and asked to participate. They were not informed of the total number and name of other experts, which is important to prevent judgement-based biases commonly associated with expert panels. All feedback from experts was anonymized before being forwarded to other experts during the subsequent Delphi rounds. 


\subsection{Derivation of the initial list of potential damage item}

To allow the initial selection of potential items related to damage in RP, the steering committee prepared a preliminary list of items on the basis existing damage scores including the Vasculitis Damage Index (VDI) (11), the IMACS Myositis Damage Index (MDI) (12), the Sjögren's Syndrome Disease Damage Index (SSDDI) (13), the SLICC/ACR Lupus Damage Index (14) and expert feedback. A total of 141 items were identified from the literature review and 12 additional items were suggested by the expert panel during preliminary discussions [Appendix A, Table S1; See the supplementary material associated with this article online].

\subsection{Delphi survey for item selection}

The Delphi method was used to maintain expert anonymity during the study and therefore prevent judgement-based biases such as dominance, conflict of interest, and group pressures that are commonly associated with expert panels. For the four-round Delphi, we used password-protected electronic questionnaires created using the Google forms survey tool. After each round, experts were provided with the aggregate responses of prior rounds. Any comment from experts during each round was sent anonymously to all other experts, so that these comments could be taken into consideration.

During the RPDAM study round 1, the experts were asked to rate the relevance of each of the potential 153 initial damage items using a 1 ("strongly disagree to inclusion in the final RPDAM index") to 10 ("strongly agree to inclusion in the final RPDAM index") Likert scale. According to the French recommendations for the development of expert consensus, we selected for round 2 all items with a median score $\geq 7$. During rounds 2,3 and 4 , we used a simplified Likert scale from 1 ("should not be included in the final RPDAM index") to 4 
("should be included in the final RPDAM index"), and the items selected for the next rounds where those with a median score $\geq 3$ on the 1 to 4 scale (first quartile).

The purpose of round 4 was to allow expert validation of items selected after the three first rounds, and to refine the final index by using further expert feedback.

\subsection{Statistical analyses}

Quantitative data were expressed as median (minimum-maximum) values and qualitative data as number of percentages. Statistical analyses were performed using the software JMP version 13 (SAS institute, Cary, NC, USA).

\section{Results}

\subsection{Characteristics of the panel of experts}

Of 44 invited experts, 24 did participate in round 1 and $22(91.7 \%)$ in rounds 2,3 and 4 . The median age of experts was 55 (range: 30-67) years. All of them were MDs and 4 had a PhD. These experts were located in France $(n=6)$, United Kingdom $(n=4)$, United States of America $(n=4)$, Spain $(n=3)$, Japan $(n=2)$, India $(n=2)$, Singapore $(n=2)$, and one of each in the Netherlands, Poland, Romania and Italy. Twelve were rheumatologists, 8 were internists, 2 were ENT specialists, 2 were dermatologists and one of each were nephrologist, pediatrician and pneumologist. All of those who had completed the 4 rounds reported having $\geq 10$ years of experience in the management of RP patients.

\subsection{Selection of items during rounds 1,2 and 3.}

The median score across all 153 potential damage items was 5.5 (1-10) on the 1 (strongly disagree to inclusion) to 10 (strongly agree) rating scale. A total of 44 items were attributed a median score $\geq 7$ and were therefore selected to enter round 2 (Table 1) [Appendix A, Table S2; See the 
supplementary material associated with this article online]. During round 2, those 44 items were graded using a simplified scale from 1 (should not be included) to 4 (should be included in the RPDAM). The median score given across those 44 items was 3 (1.5-4) (Table 2). Of those, 30 items (with a median score $\geq 3$ ) were selected for round 3 (Table 2). Among those 30 items, 9 (assessing pulmonary damage) were semantically redundant and were presented separately, with experts asked to select the most relevant wording to describe pulmonary damage. A total of 16 items with a median score $\geq 3$ were selected for round 4 (Table 2).

\subsection{Delphi round 4 and index refinement}

Of the 16 items selected during round three, 4 items regarding specific respiratory damage and 2 items regarding nose cartilage damage were still considered semantically redundant by the steering committee. These redundant items were further refined by being submitted separately to the expert panel during phase 4 . For each of these 2 domains, the experts were asked to select the most specific item. The one finally selected was the one which received the higher number of vote from the 22 experts (Table 2).The remaining 10 items were further validated by expert consensus during phase 4 (median score of 3.5 [3-4]).

During the final refinement phase, 6 additional items regarding treatment-related adverse events and potentially relevant disease-related items were discussed. Amongst them, five relevant items were selected by expert vote (median score of 3 [3-3]) (Table 2).

Based on these 4 rounds of Delphi and following the refinement phase, a total number of 17 items was selected by expert consensus and together constitute the final RPDAM (Table 3).

\section{Discussion}


Both activity and damage measuring tools are essential in clinical trials, as these allow standardization of collected data. We have previously developed a disease-specific activity score for RP (10). Here, our primary aim was to develop an index designed specifically to evaluate damage in RP patients. This tool was developed based on a multicenter and international consensus of experts involved in the care of RP patients. From an initial list of 153 potential damage items, the experts selected by consensus a final list of 17 items which together constitute the final RPDAM.

A major challenge was to distinguish adequately between items reflecting disease activity and those reflecting damage. During this study, we stressed that we considered only irreversible manifestations, rather than those that would reflect disease activity. Importantly, items regarding renal damage were not selected by expert for the final RPDAM. This is of interest because renal involvement is rare (being observed in none of the 142 patients reported in the recent French RP cohort (15)) in RP. Most experts agree that presence of renal involvement shall make one reconsider the diagnosis of RP and consider in priority alternative diagnoses such as ANCA-associated vasculitis, typically granulomatosis with polyangiitis or micropolyangiitis (MPA). Similarly, other items (mostly regarding the ENT system) such as "Nasal blockage or chronic discharge or crusting" and "Chronic sinusitis or radiologic evidence of bone destruction" were believed to be more typical of GPA than of RP and were therefore not selected by the expert panel (16).

As for other damage measuring tools such as the Vasculitis Damage Index (VDI) (11), we decided not to weight the items that constitute the final RPDAM and to favor an approach in which individual damage items would be considered as present or absent.

Among the limitations of the study are the size of the expert panel, which can be explained by the rarity of the disease and the lack of both national and international network of care for RP. 
However, one major asset of the derivation of this score is that the expert panel originated from 11 countries and reflected various medical specialties involved in the care of RP. Another limitation was the fact that some experts participated to round 2 but not to the subsequent phases. Those experts were sent several reminders for completing the study but none responded. This limitation could have been compensated by a larger panel of experts, which cannot be realistically achieved in RP. Finally, future studies will determine whether the RPDAM remains as an unweighted index or whether different weights should be applied to its individual items.

We have developed by international consensus a scoring system to evaluate damage in patients with RP, the RPDAM. From a total of 153 potential damage items, the expert panel has derived a 17 item index with the aim to support daily clinical practice, and homogenize the set of clinical tools to be used in future clinical trials. Although this index remains to be validated, both the RPDAI and the RPDAM may contribute to improve the care of patients suffering from this rare condition.

Availability of data and materials: All data generated or analysed during this study are included in this published article and its additional files.

Disclosure statement: No author has a conflict of interest regarding this manuscript.

Funding: This research did not receive any specific grant from funding agencies in the public, commercial, or not-for-profit sectors.

\section{Authorship contributions}

All authors were involved in drafting the article or revising it critically for important intellectual content, and all authors approved the final version to be published. 
Study conception and design: Philippe MERTZ, Laurent ARNAUD

Acquisition of data: Philippe MERTZ, Laurent ARNAUD

Analysis and interpretation of data: Philippe MERTZ, Alexandre BELOT, Ricard CERVERA, Tyng Yu CHUAH, Lorenzo DAGNA, Laura DAMIAN, Debashish DANDA, David D'CRUZ, Gerard ESPINOSA, Camille FRANCES, David JAYNE, Kong KOK OOI, Eugene J. KUCHARZ, Robert LEBOVICS, Isabelle MARIE, Guillaume MOULIS, Stanford PENG, Aman SHARMA, Noboru SUZUKI, Toshio TANAKA, Ronald VAN VOLLENHOVEN, Jean SIBILIA, Jacques Eric GOTTENBERG, François CHASSET, Laurent ARNAUD

Appendix A. Supplementary data

Supplementary data (Tables S1-S2) associated with this article can be found in the online version at ... 


\section{REFERENCES}

1. Arnaud L, Mathian A, Haroche J, Gorochov G, Amoura Z. Pathogenesis of relapsing polychondritis: a 2013 update. Autoimmun Rev. 2014;13:90-5.

2. Shimizu Y, Kamiyoshihara M, Okajo J, Ishii Y, Takise A. Tracheobronchial stenosis evaluated by inspiratory and expiratory three-dimensional computed tomography and impulse oscillation with three-dimensional color imaging in a patient with relapsing polychondritis. J Biol Regul Homeost Agents. 2014 ;28:325-31.

3. Le Besnerais M, Arnaud L, Boutémy J, Bienvenu B, Lévesque H, Amoura Z, et al. Aortic involvement in relapsing polychondritis. Joint Bone Spine. 2018 ;85:345-51.

4. Francès C, el Rassi R, Laporte JL, Rybojad M, Papo T, Piette JC. Dermatologic manifestations of relapsing polychondritis. A study of 200 cases at a single center. Medicine (Baltimore). $2001 ; 80: 173-9$.

5. Kingdon J, Roscamp J, Sangle S, D'Cruz D. Relapsing polychondritis: a clinical review for rheumatologists. Rheumatology (Oxford). $2018 ; 57: 1525-32$.

6. Dion J, Leroux G, Mouthon L, Piette J-C, Costedoat-Chalumeau N. Relapsing polychondritis: What's new in 2017?. Rev Med Interne. 2018 ;39:400-7.

7. Liu W, Jiang H, Jing H, Mao B. An unusual cause of fever of unknown origin with enlarged lymph nodes-relapsing polychondritis: A case report. Medicine (Baltimore). $2017 ; 96: \mathrm{e} 8734$. 
8. Mathew SD, Battafarano DF, Morris MJ. Relapsing polychondritis in the Department of Defense population and review of the literature. Semin Arthritis Rheum. $2012 ; 42: 70$ 83.

9. Hazra N, Dregan A, Charlton J, Gulliford MC, D’Cruz DP. Incidence and mortality of relapsing polychondritis in the UK: a population-based cohort study. Rheumatology (Oxford). $2015 ; 54: 2181-7$.

10. Arnaud L, Devilliers H, Peng SL, Mathian A, Costedoat-Chalumeau N, Buckner J, et al. The Relapsing Polychondritis Disease Activity Index: development of a disease activity score for relapsing polychondritis. Autoimmun Rev. $2012 ; 12: 204-9$.

11. Exley AR, Bacon PA, Luqmani RA, Kitas GD, Gordon C, Savage CO, et al. Development and initial validation of the Vasculitis Damage Index for the standardized clinical assessment of damage in the systemic vasculitides. Arthritis Rheum. 1997 ;40:371-80.

12. Isenberg DA, Allen E, Farewell V, Ehrenstein MR, Hanna MG, Lundberg IE, et al. International consensus outcome measures for patients with idiopathic inflammatory myopathies. Development and initial validation of myositis activity and damage indices in patients with adult onset disease. Rheumatology (Oxford). 2004 ;43:49-54.

13. Vitali C, Palombi G, Baldini C, Benucci M, Bombardieri S, Covelli M, et al. Sjögren's Syndrome Disease Damage Index and disease activity index: scoring systems for the assessment of disease damage and disease activity in Sjögren's syndrome, derived from an analysis of a cohort of Italian patients. Arthritis Rheum. 2007 ;56:2223-31.

14. Gladman D, Ginzler E, Goldsmith C, Fortin P, Liang M, Urowitz M, et al. The development and initial validation of the Systemic Lupus International Collaborating 
Clinics/American College of Rheumatology damage index for systemic lupus erythematosus. Arthritis Rheum. 1996 ;39:363-9.

15. Dion J, Costedoat-Chalumeau N, Sène D, Cohen-Bittan J, Leroux G, Dion C, et al. Relapsing Polychondritis Can Be Characterized by Three Different Clinical Phenotypes: Analysis of a Recent Series of 142 Patients. Arthritis Rheumatol. 2016;68:2992-3001.

16. Guntupalli L, Patel K, Faraji F, Brunworth JD. Autoimmune-related nasal septum perforation: A case report and systematic review. Allergy Rhinol (Providence). 2017 $1 ; 8: 40-4$. 


\section{TABLES}

Table 1: Validated items during round 1

\begin{tabular}{|c|c|}
\hline DAMAGE ITEMS & $\begin{array}{l}\text { RATING: } \\
\text { median (range) }\end{array}$ \\
\hline \multicolumn{2}{|l|}{ MUSCULO-SKELETAL } \\
\hline $\begin{array}{l}\text { Deforming or erosive arthritis (including reducible deformities, } \\
\text { excluding avascular necrosis) }\end{array}$ & $7.5(2-10)$ \\
\hline Avascular necrosis (regardless of treatment) & $8(1-10)$ \\
\hline Permanent chest wall deformities & $7(1-10)$ \\
\hline \multicolumn{2}{|l|}{ ENT } \\
\hline Sensorineural hearing loss & $10(7-10)$ \\
\hline Conductive hearing loss & $9(5-10)$ \\
\hline Permanent auricular deformities & $10(2-10)$ \\
\hline Permanent auricular cartilage deformities & $10(7-10)$ \\
\hline Nasal bridge collapse or septal perforation & $9(7-10)$ \\
\hline Permanent nose deformities & $9.5(1-10)$ \\
\hline Permanent nose cartilage deformities & $10(7-10)$ \\
\hline Nasal blockage or chronic discharge or crusting & $7(2-10)$ \\
\hline Chronic sinusitis or radiologic evidence of bone destruction & $7(1-10)$ \\
\hline Vestibular syndrome & $7(3-10)$ \\
\hline \multicolumn{2}{|l|}{ PULMONARY } \\
\hline Dysphonia & $8(4-10)$ \\
\hline Upper airway obstruction requiring surgery & $10(2-10)$ \\
\hline Upper airway obstruction not requiring surgery & $9(2-10)$ \\
\hline Symptomatic upper airway obstruction & $9(4-10)$ \\
\hline Tracheomalacia & $10(7-10)$ \\
\hline Obstructive syndrome due to stenosis & $9(3-10)$ \\
\hline Obstructive syndrome due to malacia & $9(2-10)$ \\
\hline Obstructive syndrome : stenosis/ malacia & $9.5(4-10)$ \\
\hline Obstructive syndrome (symptomatic) : stenosis/malacia & $10(3-10)$ \\
\hline Laryngeal obstructive syndrome & $9(2-10)$ \\
\hline Tracheal obstructive syndrome & $9(2-10)$ \\
\hline Bronchial obstructive syndrome & $9(2-10)$ \\
\hline Obstructive syndrome (laryngeal, tracheal or bronchial) & $10(3-10)$ \\
\hline Continuous oxygen dependency & $8(1-10)$ \\
\hline Significant chronic breathlessness & $7(2-10)$ \\
\hline Impaired pulmonary function tests & $7(1-10)$ \\
\hline \multicolumn{2}{|l|}{ CARDIOVASCULAR } \\
\hline Aortic root dilatation & $8(1-10)$ \\
\hline Valvular disease & $7(1-10)$ \\
\hline Second episode of major tissue loss & $8(1-10)$ \\
\hline Major tissue loss & $7.5(1-10)$ \\
\hline \multicolumn{2}{|l|}{ RENAL } \\
\hline End-stage renal failure & $7(1-10)$ \\
\hline Dialysis & $7(1-10)$ \\
\hline Renal transplant & $7(1-10)$ \\
\hline
\end{tabular}


Scleral thinning (scleromalacia)

Scleral thinning

Scleromalacia

Optic nerve atrophy

Blindness in second eye

Blindness (in one or two eyes)

Blindness in 1 eye

Orbital wall destruction
$8(1-10)$

$7.5(1-10)$

$7.5(1-10)$

$8(1-10)$

$8(1-10)$

$8(1-10)$

$7(1-10)$

$7.5(1-10)$ 
Table 2: Validated items during rounds 2,3 and 4

\begin{tabular}{|c|c|c|c|}
\hline \multirow{2}{*}{ DAMAGE ITEMS } & ROUND 2 & ROUND 3 & ROUND 4 \\
\hline & \multicolumn{3}{|c|}{ RANGE of ratings: $0-4$} \\
\hline \multicolumn{4}{|l|}{ MUSCULO-SKELETAL } \\
\hline Avascular necrosis (regardless of treatment) & $3(1-4)$ & $2.5(1-4)$ & - \\
\hline Permanent chest wall deformities & $3(1-4)$ & $3(1-4)$ & $3(2-4)$ \\
\hline $\begin{array}{l}\text { Deforming or erosive arthritis (including } \\
\text { reducible deformities, excluding avascular } \\
\text { necrosis) }\end{array}$ & $2.5(1-4)$ & . & - \\
\hline \multicolumn{4}{|l|}{ ENT } \\
\hline Sensorineural hearing loss & $4(2-4)$ & $4(3-4)$ & $4(1-4)$ \\
\hline Conductive hearing loss & 4 1-4) & $3(2-4)$ & $4(1-4)$ \\
\hline Permanent auricular cartilage deformities & $4(1-4)$ & $4(3-4)$ & $4(3-4)$ \\
\hline Permanent auricular deformities & $2(1-4)$ & - & - \\
\hline Nasal bridge collapse or septal perforation & $4(3-4)$ & $4(1-4)$ & $86.4 \% \div$ \\
\hline Permanent nose cartilage deformities & $4(1-4)$ & $4(3-4)$ & $\ddagger$ \\
\hline Permanent nose deformities & $2.5(1-4)$ & - & - \\
\hline Nasal blockage or chronic discharge or crusting & $3(1-4)$ & $1(1-3)$ & - \\
\hline $\begin{array}{l}\text { Chronic sinusitis or radiologic evidence of bone } \\
\text { destruction }\end{array}$ & $3(1-4)$ & $1.5(1-3)$ & - \\
\hline Vestibular syndrome & $3(1-4)$ & $2(1-4)$ & - \\
\hline \multicolumn{4}{|l|}{ PULMONARY } \\
\hline Dysphonia & $3.5(2-4)$ & $3(1-4)$ & $3(2-4)$ \\
\hline Upper airway obstruction requiring surgery & $3(1-4)$ & $\dagger$ & - \\
\hline Upper airway obstruction not requiring surgery & $1.5(1-4)$ & - & - \\
\hline Symptomatic upper airway obstruction & $2(1-4)$ & - & - \\
\hline Tracheomalacia & 4 3-4) & $\dagger$ & - \\
\hline Obstructive syndrome : stenosis/malacia & $3(1-4)$ & $\dagger$ & - \\
\hline $\begin{array}{l}\text { Obstructive syndrome (symptomatic) : stenosis/ } \\
\text { malacia }\end{array}$ & $3(1-4)$ & $\dagger$ & - \\
\hline Obstructive syndrome due to stenosis & $2(1-4)$ & - & - \\
\hline Obstructive syndrome due to malacia & $2(1-4)$ & - & - \\
\hline Laryngeal obstructive syndrome & $3(1-4)$ & $\dagger$ & - \\
\hline Tracheal obstructive syndrome & $3(1-4)$ & $\dagger$ & - \\
\hline Bronchial obstructive syndrome & $3(1-4)$ & $\dagger$ & - \\
\hline $\begin{array}{l}\text { Obstructive syndrome (laryngeal, tracheal or } \\
\text { bronchial) }\end{array}$ & $3(1-4)$ & $45.5 \% \dagger$ & $90.9 \% \S$ \\
\hline Continuous oxygen dependency & $3(1-4)$ & $3(1-4)$ & $\S$ \\
\hline Significant chronic breathlessness & $3(1-4)$ & $3(1-4)$ & $\S$ \\
\hline Impaired pulmonary function tests & $3(1-4)$ & $3(1-4)$ & $\S$ \\
\hline \multicolumn{4}{|l|}{ CARDIOVASCULAR } \\
\hline Aortic root dilatation & $4(2-4)$ & $3(2-4)$ & $3(2-4)$ \\
\hline Major tissue loss & $3(1-4)$ & $3(1-4)$ & $3(1-4)$ \\
\hline Second episode of major tissue loss & $3(1-4)$ & $2(1-3)$ & - \\
\hline Valvular disease & $3(2-4)$ & - & - \\
\hline \multicolumn{4}{|l|}{ OCULAR } \\
\hline Scleral thinning & $1.5(1-4)$ & - & - \\
\hline Scleromalacia & $2(1-4)$ & - & - \\
\hline Scleral thinning (scleromalacia) & $3.5(1-4)$ & $3.5(1-4)$ & $4(2-4)$ \\
\hline
\end{tabular}


Optic nerve atrophy

Blindness in one eye

3 (1-4)

$2(1-4)$

Blindness in second eye

$2(1-4)$

Blindness (in one or two eyes)

3 (1-4)

$3(1-4)$

$2.5(1-4)$

Orbital wall destruction

4 (2-4)

RENAL

End-stage renal failure

Dialysis

$2(1-4)$

$2(1-4)$

Renal transplant

$2(1-4)$

TOTAL NUMBER OF ITEMS

SELECTED FOR THE NEXT ROUND

30

16

12

$\dagger$ Redundant pulmonary damage items voted together during phase 3: Obstructive syndrome (laryngeal, tracheal or bronchial) was selected with a total score of $45.5 \%$

$\ddagger$ Redundant nose cartilage damage voted together during phase 4: Nasal bridge collapse or septal perforation was selected with a total score of $86.4 \%$

$\S$ Redundant pulmonary damage items voted together during phase 4: Obstructive syndrome (laryngeal, tracheal or bronchial) was selected with a total score of $90.9 \%$ 
Table 3: Final RPDAM

Relapsing Polychondritis Damage Index

(RPDAM)

\begin{tabular}{lll}
\hline \multicolumn{1}{c}{ EAR } & \multicolumn{1}{c}{ NOSE } & \multicolumn{1}{c}{ EYE } \\
\hline$\square$ Permanent auricular & $\begin{array}{l}\square \text { Nasal bridge collapse } \\
\text { or septal perforation }\end{array}$ & $\square$ Scleral thinning \\
cartilage deformities & & $\begin{array}{l}\text { Blindness (in one of two } \\
\text { eyes) }\end{array}$ \\
$\square$ Sensorineural hearing loss & $\square$ Orbital wall destruction \\
$\square$ Conductive hearing loss & \\
$\square$ Permanent vestibular & \\
syndrome &
\end{tabular}

\begin{tabular}{lll}
\hline \multicolumn{1}{c}{ RESPIRATORY } & CARDIOVASCULAR & \multicolumn{1}{c}{ HAEMATOLOGICAL } \\
\hline$\square$ Permanent chest wall & $\square$ Aortic root dilatation & $\begin{array}{l}\square \text { Transfusion dependency } \\
\text { in the context of a } \\
\text { deformities }\end{array}$ \\
$\square$ Dysphonia & $\square$ Left ventricular & $\begin{array}{l}\text { myelodysplastic syndrome } \\
\text { dysfunction }\end{array}$ \\
$\square$ Obstructive syndrome & $\square$ Major tissue loss \\
(laryngeal, tracheal or & & \\
bronchial) &
\end{tabular}

Osteoporosis with fractures or vertebral collapse

Avascular necrosis

Damage defined as irreversible manifestations of the disease that are unlikely to benefit from treatment escalation, ascertained by clinical assessment and present for at least 3 months.

All damage manifestations reported in the RPDAM score have to occur after diagnosis of relapsing polychondritis. 